\title{
Violência Urbana, Insegurança e Medo: Da Necessidade de Estratégias Coletivas
}

\author{
Urban Violence, Insecurity And Fear: \\ The Need For Collective Strategies
}

Violencia Urbana, Inseguridad Y Miedo: De La Necesidad De Estrategias Colectivas

Edinete Maria Rosa, Lídio de Souza,

Daniela Moraes de

Oliveira \& Bianca

Izoton Coelho

Universidade Federal do Espírito Santo

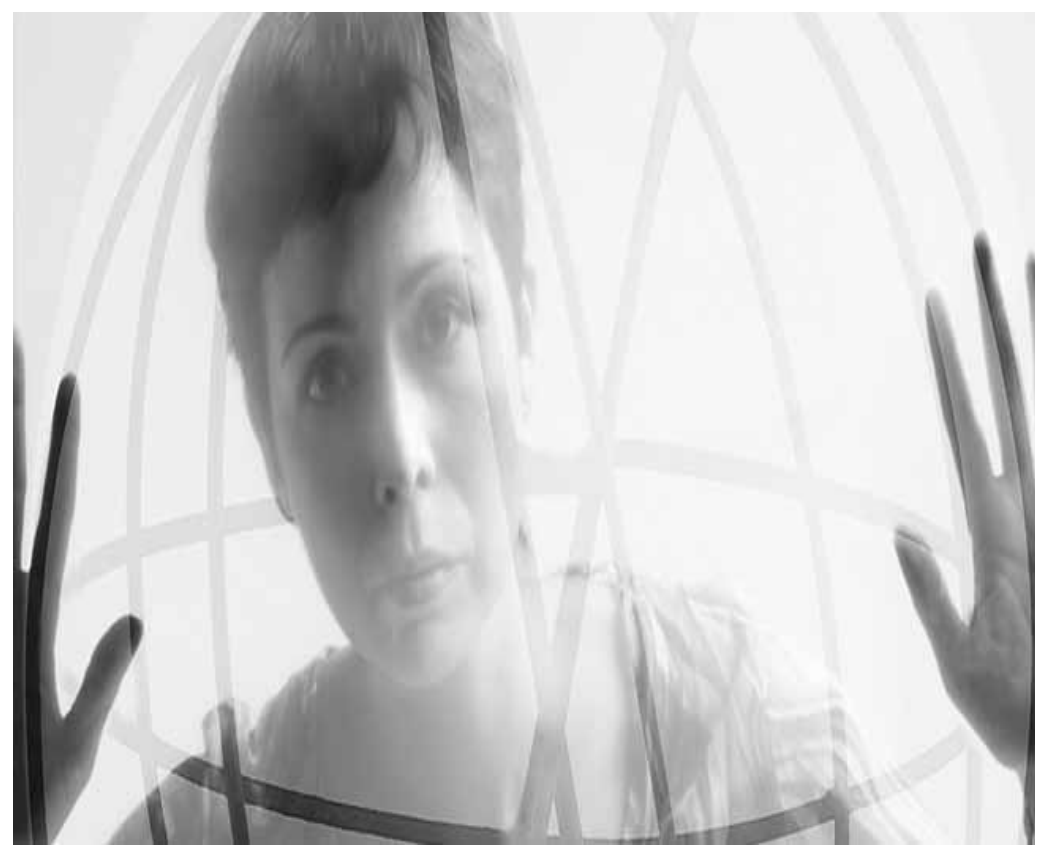


Resumo: A pesquisa objetivou conhecer as estratégias de combate à violência urbana propostas por moradores de um bairro situado em uma região metropolitana brasileira. Os dados foram coletados por meio de entrevistas realizadas com nove moradores que residiam no bairro, por pelo menos dez anos, orientadas por um roteiro semiestruturado e também por meio de um seminário promovido pelos pesquisadores com a participação de catorze moradores. As informações obtidas foram sistematizadas através de análise de conteúdo e revelaram a existência de sentimentos de medo e insegurança bem como a predominância de estratégias individuais para o combate à violência no bairro. Além disso, verificou-se que a participação coletiva mobilizada pelos problemas enfrentados pelos moradores é frágil e necessita ser estimulada visando à construção de soluções mais duradouras, preservando-se a utilização dos espaços públicos por todos e o estado de direito.

Palavras-chave: Violência. Medo. Ansiedade social. Comportamento coletivo. Problemas sociais.

Abstract: The research aimed to know the strategies to combat urban violence proposed by the residents of a neighborhood located in a Brazilian metropolitan area. Data were collected through interviews with nine residents who have been living in the neighborhood for at least ten years, driven by a semi-structured script. Data were also collected by a seminar promoted by researchers with the participation of fourteen residents. The data obtained were systematized through content analysis and revealed the existence of feelings of fear and insecurity, as well as the dominance of individual strategies to combat violence in the neighborhood. Furthermore, it was found that the collective participation in view of the problems faced by the residents is fragile and the construction of more durable solutions needs to be stimulated in order to preserve the use of public spaces by all and the rule of law.

Keywords: Violence. Fear. Social anxiety. Collective Behavior. Social issues.

Resumen: La investigación ha objetivado conocer las estrategias de combate a la violencia urbana propuestas por residentes de un barrio ubicado en una región metropolitana brasileña. Los datos han sido recolectados a través de entrevistas llevadas a cabo con nueve residentes que vivían en el barrio por, al menos, diez años, orientadas por un guión semiestructurado y también a través de un seminario promovido por los investigadores con la participación de catorce residentes. Las informaciones obtenidas han sido sistematizadas a través de análisis de contenido y han revelado la existencia de sentimientos de miedo e inseguridad, así como la predominancia de estrategias individuales para el combate a la violencia en el barrio. Más allá de ello, se ha verificado que la participación colectiva movilizada por los problemas enfrentados por los residentes es frágil y necesita ser estimulada objetivándose la construcción de soluciones más duraderas, preservándose la utilización de los espacios públicos por todos y el estado de derecho.

Palabras clave: Violencia urbana. Miedo. Ansiedad social. Conducta colectiva. Problemas sociales.

Desde as últimas décadas do século passado, a violência urbana ganhou amplo espaço no debate público que procura formas de enfrentamento e de prevenção de ocorrências cujas consequências não distinguem classe social. Várias iniciativas surgiram em todo o País, e parte significativa da produção científica nas ciências sociais dedicou-se a descrever esse fenômeno. Hughes lembra que o crescimento da violência urbana, principalmente nas regiões metropolitanas, levou "a uma redefinição do problema como uma das principais questões sociais urbanas, no final do século XX, estreitamente vinculada às condições sociais e urbanísticas desses aglomerados" (2004, p. 96).
Os meios de comunicação tiveram uma forte participação ao difundir as estatísticas sobre violência, mais especificamente sobre criminalidade, e contribuíram de forma inequívoca para produzir representações sobre insegurança (Mena \& Vega, 2006), que produz efeitos perversos sobre a participação nos espaços públicos. Segundo Schilling,

a sucessão sem-fim de casos que se apresentam no cenário urbano cria a sensação profunda de insegurança e medo, provocando um retraimento generalizado das pessoas, que se cercam em suas casas, abandonando em maior ou menor medida os espaços públicos. Constituímonos como cidadãos atemorizados, com fraca participação pública, minando, assim, os esforços pela ocupação de espaços na política e na gestão da coisa 
pública, imprescindíveis para a construção democrática (2004, p. 48)

Hopenhayn também compartilha de tal entendimento ao afirmar que "o aumento da insegurança cidadã não somente reflete os problemas de desintegração social mas também reforça essa desintegração: enfraquece laços e sentimentos de pertença à comunidade ou à sociedade e debilita também as normas de confiança e reciprocidade próprias de uma cultura cívica" (2002, p. 15).

No entanto, é fácil verificar que não há consenso sobre a evolução dos indicadores sobre violência e criminalidade. Njaine, Souza, Souza Minayo e Assis (1997) já indicaram vários fatores que influenciam a credibilidade de tais indicadores, dentre os quais destacamos: a inexistência de uniformidade nos critérios utilizados para a realização dos registros, a conhecida subnotificação das ocorrências e a manipulação das estatísticas com objetivos políticos.

Nas estatísticas divulgadas a partir da década de 1990, o Estado do Espírito Santo tem sido apontado como um dos mais violentos do Brasil, informação que produz grande impacto nos meios de comunicação. No entanto, trabalho desenvolvido recentemente por Peixoto, Lima e Ottoni (2004), tomando como referência os dados oficiais sobre violência e criminalidade, indica que a violência no Estado tem decrescido, embora com taxas aquém do desejável. O que é importante acentuar é que a redução identificada não repercute de maneira positiva na modulação dos sentimentos de insegurança e medo, algo semelhante ao que ocorre na Cidade do México (Lozano, 2006). Embora a cidade de Vitória tenha passado a figurar entre as mais violentas, constatação presente em vários estudos (Adorno, 2002; Souza, 2005; Souza \& Lima, 2007), a violência na cidade não se distribui de modo homogêneo, revelando áreas com baixa e alta densidade criminal.
Apesar de se verificar uma ligeira redução no índice de violência nas cidades metropolitanas brasileiras nos últimos anos, observa-se que, nas cidades do interior, ela tem aumentado, conforme mostra o Mapa da Violência 2011 (Waiselfisz, 2011). Registra-se também um aumento da violência urbana em países como Nicarágua, Guatemala, Colômbia e El Salvador (Moser, Winton, \& Moser, 2001). Moser e Mcilwaine (2006) lembram que a América Latina tem um nível extremamente elevado de violência considerando-se as taxas de homicídios em relação a outros países. Conforme as autoras, a taxa de homicídio doloso aumentou 50\% em relação ao início dos anos 80 até meados dos anos 90, com aumentos marcados no Panamá, no Peru e na Colômbia. Contudo, há de se considerar que a definição, a natureza e a extensão da violência urbana variam entre e dentro dos países (Moser et al., 2001; Moser \& Mcilwaine, 2006).

Embora a violência urbana seja um fenômeno de dispersa definição, sua representação gira em torno da ameaça a duas condições básicas do sentimento de segurança existencial: a integridade física e a garantia patrimonial (Silva, 2004). Apesar de afetar a vida cotidiana de grande contingente de pessoas, o debate em torno das possíveis soluções para o problema da violência urbana tem sido ainda incipiente e pouco tem mobilizado os organismos sociais legitimados, sejam eles pertencentes à esfera governamental ou não. Moser e Mcilwaine detectaram que parte da dificuldade no combate à violência está localizada na disparidade existente entre as pesquisas acadêmicas e o foco de interesse dos governos. Enquanto as pesquisas enfatizam a complexidade do fenômeno, "a política centrada busca categorizar os tipos de violência, medir seus custos, identificar suas consequências em termos de taxas de homicídio e vitimização" (2006, p. 101). As autoras destacam que o maior desafio diz respeito à identificação de um quadro 
político que possa conciliar a complexidade da violência identificada pela população com as soluções específicas que os governos propõem.

Devido ao crescente reconhecimento da inter-relação entre diferentes tipos de violência, a tendência das últimas décadas tem sido deslocar o foco de ações pontuais de controle destinadas a tipos específicos de violência para ações que se concentram na sua prevenção (Moser \& Mcilwaine, 2006). Essas últimas ações, expõem os autores, caracterizam-se pela atuação nas causas estruturais subjacentes ao fenômeno da violência, no apoio às vítimas e na punição dos autores da violência, enfatizando a negociação de resolução pacífica de conflitos por meio da promoção dos direitos humanos, além de trabalhar com as comunidades fortalecendo ou reconstruindo os níveis de capital social.

Machado da Silva (2003), no entanto, enfatiza que, apesar de as práticas políticas serem apoiadas em uma bateria de instrumentos legais, elas permanecem muito rarefeitas e continuam dependendo de pressão social. Visto que não haverá soluções eficazes com ações isoladas (Soares, 2005), é preciso entender o próprio cotidiano como oportunidade única de investimento no protagonismo pessoal e grupal (Santos, 2005), sem o qual as possíveis formas coletivas de solução para os problemas cotidianos se enfraquecem. É na prática cotidiana da participação e engajamento nos projetos comunitários que as pessoas se percebem como cidadãos e cidadãs corresponsáveis pela busca do bem comum. Machado da Silva enfatiza: "cidadãos(ãs) não nascem feitos(as), surgem na luta, no conflito social que, dependendo de seu encaminhamento, pode produzir uma democratização das relações sociais..." (2003, p.27).

Portanto, a existência e a insistência de um fenômeno que afeta não só a um indivíduo, mas de formas e intensidades diferentes, a coletividade, condiciona a procura por soluções pertinentes no espaço coletivo. E para que esse espaço de discussão de estratégias e soluções possa se estabelecer, faz-se necessário que ele seja eminentemente político, isto é, que a participação real de todos seja garantida na formulação de uma vontade que seja geral e efetivamente autônoma. Essa "politização do social, do cultural e mesmo do pessoal abre um campo imenso para o exercício da cidadania (...)" (Santos, 2005, p.263). Na busca da construção ativa da cidadania, há de se considerar que "a comunidade assenta, na obrigação política horizontal entre indivíduos ou grupos sociais e na solidariedade que dela decorre, uma solidariedade participativa e concreta, isto é, socialmente contextualizada" (Santos, 2005, p. 244).

Alguns estudos sobre programas de contenção relacionados à violência urbana, tal como o Programa de Controle de Homicídios Fica Vivo, existente na cidade de Belo Horizonte (MG), e ações promovidas pela Prefeitura de Diadema (SP) destacam a fundamental importância da participação popular na luta contra a violência. Segundo Silveira, Silva e Beato, deve-se "valorizar e estimular a participação da comunidade na elaboração da proposta de intervenção, na operacionalização e gestão do modelo e na sua avaliação" (2006, p. 80). Além da participação da própria comunidade nas ações de enfrentamento da violência, é possível ressaltar o importante papel que outros setores da sociedade, e até mesmo do Estado, podem exercer nesse contexto, principalmente as Prefeituras Municipais. Como informa Miraglia,

a prefeitura é o braço do poder público mais próximo à população, é onde se dá a prestação cotidiana de serviços, é, também, quem conhece os problemas e conflitos da comunidade mais de perto e pode, portanto, solucioná-los com maior 
agilidade (...). A proximidade com a comunidade agrega outro capital ao poder municipal: a capacidade de mobilização e articulação da população em geral (2006, p.89)

Além disso, a autora afirma que "estabelecer e liderar parcerias com diversos setores da sociedade civil organizada (lideranças locais, lideranças religiosas, associações de bairro, ONGs, etc.) (...), além de ampliar os canais de escuta e engajar a sociedade como um todo no planejamento e execução das políticas de segurança" (Miraglia, 2006, p.89), são passos fundamentais que as prefeituras devem tomar para que o planejamento e a prática de ações sejam eficazes no combate à violência.

O que se vê na realidade é que, quando esses mecanismos coletivos enfraquecem, o debate em torno da violência tende a expressar com maior intensidade a exclusão social concretizada na discriminação daqueles que já carregam o estigma de potenciais marginais e delinquentes, como salientado por Sá:

A exclusão social, implicando a diferenciação entre nós e os outros, passa a ser cada vez mais nítida, verificandose (...) uma distinção muito clara entre o cidadão e os outros, os que são culturalmente distintos - o emigrante, os que são visualmente diferenciados e economicamente mais pobres (2000, p.

03)

Como a violência geralmente está associada à ação dos que vem de fora - os outros, os estrangeiros (Zaluar, 1994; Velho, 1991; Souza, 1995) -, os sentimentos de medo e insegurança que dela decorrem alimentam

um sentimento de suspeita para com os demais ou para com os diferentes, sobretudo se são jovens, homens e de baixa renda. Muda o desenho urbano ao proliferarem as grades e os condomínios fechados e ao levar as atividades comerciais a se concentrarem em grandes centros (malls), entre outras coisas, porque ali estão ao resguardo de assaltos e acidentes (Hopenhayn, 2002, p.15)

Tendo em vista esses aspectos e considerando que a avaliação feita pelas vítimas sobre os acontecimentos cotidianos é fortemente mediada pelo medo e pela ansiedade (Lozano, 2006), esta pesquisa objetivou conhecer as estratégias individuais e coletivas de combate à violência urbana a partir do discurso de pessoas que foram por ela afetadas, direta ou indiretamente.

\section{Método}

\section{Participantes}

\section{Entrevistas}

Participaram do estudo nove moradores de um bairro situado em uma região metropolitana brasileira atingido pela divulgação midiática de um aumento substancial no índice de violência naquele local. O critério para a inclusão no grupo de participantes foi residir no bairro e possuir um tempo de moradia igual ou superior a 10 anos. O contato com os participantes foi feito por meio de conversas informais junto a proprietários e frequentadores de estabelecimentos comerciais, contando-se com a intermediação do Centro de Convivência para Idosos e da associação de moradores do bairro.

Foram estabelecidos vários contatos com a polícia civil presente no bairro com o objetivo de obter dados referentes aos índices de violência, porém tais dados foram negados aos pesquisadores. Como já afirmamos acima, os índices de violência não guardam correspondência com o sentimento de insegurança. Tanto é assim, que um estudo realizado na cidade, utilizando dados relativos ao período 2000-2003, com o objetivo de verificar se há correlação entre o Índice de Qualidade Urbana com a ocorrência de violência, indica que a região administrativa 
onde se situa o bairro em que o estudo foi realizado não é a mais violenta da cidade. No que se refere aos homicídios, o bairro se situa na sexta posição no ranking das sete regiões administrativas. Os dados fornecidos permitem verificar também que o tipo de violência mais significativo no bairro é constituído pelos acidentes de trânsito e atropelamentos (Bastos, et al., 2009). No entanto, é importante destacar que, nos últimos anos, nota-se a crescente divulgação, pelos meios de comunicação, de episódios violentos no bairro.

Abaixo descrevemos sucintamente as principais características dos participantes, que foram identificados com a letra $m$, da palavra morador, seguida do número correspondente à ordem de realização das entrevistas. Os entrevistados tinham a idade média de 50 anos; cinco eram do sexo masculino e quatro do sexo feminino e com tempo de moradia no bairro variando de 11 a 32 anos, tendo sido a média de 21.7 anos e a moda de 23 anos de moradia.

M1: sexo masculino, 41 anos, funcionário público, residente há 11 anos no bairro; M2: sexo masculino, 53 anos, comerciante, residente há 23 anos; M3: sexo masculino, 57 anos, coronel aposentado da polícia militar, residente há 23 anos; M4: sexo feminino, 47 anos, funcionária pública estadual, residente há 21 anos; M5: sexo feminino, 42 anos, trabalhadora autônoma, residente há 18 anos; M6: sexo masculino, 45 anos, comerciante, residente há 32 anos; M7: sexo feminino, 53 anos, estudante, residente há 23 anos; M8: sexo feminino, 66 anos, advogada aposentada, residente há 32 anos; M9: sexo masculino, 46 anos, funcionário público, residente há 13 anos.

\section{Seminário}

O grupo de participantes do seminário foi composto por 20 pessoas, predominando a participação de moradores do bairro representados por 14 pessoas. Os 6 participantes restantes e 1 professor convidado compunham a equipe de pesquisadores. Dentre os 14 participantes do bairro, 4 eram do sexo feminino e 10 do sexo masculino. Destes, 2 homens eram trabalhadores da guarda municipal (além de moradores), 8 eram integrantes da associação de moradores (7 homens e 1 mulher), e 4 deles eram moradores sem participação em movimentos comunitários (3 mulheres e 1 homem).

\section{Coleta de dados}

As entrevistas foram orientadas por um roteiro semiestruturado contendo questões que focalizavam as experiências associadas à ocorrência de violência e as estratégias utilizadas pelos moradores. Resumidamente, o roteiro procurou contemplar os seguintes itens de informação: 1) dados pessoais, tempo de moradia, 2) mudança para o bairro, vivência e avaliação, 3) avaliação sobre aspectos positivos e negativos, demandas e formas de organização, 4) ocorrência e tipificação da violência, estratégias coletivas e individuais e 5) avaliação da atuação dos órgãos de segurança pública.

Durante a realização do seminário, as questões propostas aos participantes consistiam em: a) ações emergenciais necessárias dependentes da atuação dos órgãos públicos, b) ações emergenciais necessárias e de iniciativa do coletivo de moradores, c) ações emergenciais necessárias à assistência às vítimas e d) ações emergenciais necessárias para as equipes da polícia e da Guarda Municipal que atuam no bairro.

\section{Procedimentos}

Na primeira etapa, foram feitos contatos com a associação de moradores do bairro visando a obter dados que caracterizassem o bairro e a organização dos moradores, a conhecer 
as ações coletivas empreendidas pelos moradores para combater a violência urbana bem como a obter as primeiras indicações para as entrevistas.

Após a apresentação da proposta de pesquisa e com o apoio da associação de moradores, foram feitos os primeiros contatos individuais com os participantes a fim de obter o seu consentimento. Após a entrevista com os primeiros participantes, foram solicitadas a estes outras indicações de pessoas que residiam no bairro há pelo menos 10 anos. As entrevistas obedeceram às normas éticas que regulam a pesquisa com humanos e só foram realizadas e gravadas após o consentimento dos participantes. Avaliamos que os procedimentos utilizados, bem como os conteúdos focalizados, não apresentaram qualquer tipo de risco aos participantes.

As entrevistas foram gravadas e, após transcrição, submetidas à análise de conteúdo. O método de análise de conteúdo proposto por Bardin (1995) orienta que, após a transcrição e a exaustiva leitura do material, os dados sejam organizados por temas que orientam a análise. Os conteúdos que emergem no diálogo com os participantes são assim reunidos em categorias que vão indicando os sentidos das experiências narradas.

Na segunda etapa foi realizado um seminário - na Unidade Básica de Saúde -, planejado juntamente à associação de moradores, com o objetivo de colocar em discussão os dados obtidos na primeira etapa a respeito da violência no bairro, bem como de coletar dados sobre as formas de enfrentamento originadas nas discussões coletivas sobre violência urbana.

O seminário foi iniciado com a apresentação das informações obtidas na primeira etapa da pesquisa, seguida da palestra de um professor convidado, estudioso de questões relacionadas ao tema. Após a palestra, organizou-se um debate em torno do levantamento das estratégias coletivas para o enfrentamento da violência.

A viabilização desse debate entre os participantes foi delineada a partir de alguns referenciais metodológicos da pesquisa-ação e da pesquisa participante, que enfatizam a importância da articulação entre pesquisa e prática, bem como da redução da distância entre pesquisador e pesquisado (Gomes, 1987; Freire, 2000). A pesquisa-ação é definida por Thiollent como "(...) um tipo de pesquisa com base empírica que é concebida e realizada em estreita associação com uma ação ou com a resolução de um problema coletivo e no qual os pesquisadores e participantes representativos da situação ou do problema estão envolvidos de modo cooperativo ou participativo" (1985, p. 14). A pesquisa participante, por sua vez, objetiva uma efetiva participação da comunidade na análise de sua própria realidade, com vistas ao benefício dos participantes da investigação (Brandão, 1985). Na realização desta pesquisa, ambos os referenciais se conjugam na preocupação de apreender a sociedade do ponto de vista do vivido (Sawaia, 1996, p. 41) para, assim, buscar ações efetivas para o enfrentamento dos problemas.

A fim de que as discussões relacionadas ao enfrentamento coletivo da violência no bairro estudado fossem estimuladas e que estratégias pudessem surgir de maneira efetiva, os participantes presentes foram divididos em pequenos subgrupos, que tiveram como tarefa responder a uma questão anteriormente formulada pelos pesquisadores e, logo após, compartilhar com o grupo maior as soluções encontradas.

\section{Resultados}

\section{Um bairro que nasce da iniciativa privada}


Inicialmente, os dados obtidos possibilitaram recompor a história do bairro, suas configurações atuais no que se refere a aspectos como educação, saúde, segurança, assim como da organização dos moradores e de possíveis ações já efetivadas por eles ou pelos seus representantes (associação de moradores, vereadores do bairro e o próprio governo municipal) para prevenção e combate à violência no local.

O bairro surgiu por iniciativa privada de um corretor de imóveis que, em 1948, comprou a área onde está situado, porém, somente em 1967 foram construídas as primeiras cem casas do loteamento. As casas foram compradas, em sua maioria, por funcionários de uma grande empresa instalada nas proximidades.

O crescimento do bairro residencial foi acelerado, mas sua infraestrutura não seguiu o mesmo ritmo. No início, não havia ruas pavimentadas, a iluminação se restringia à única rua de acesso ao bairro e havia apenas uma escola com duas salas de aula. Não havia linhas de ônibus, o que obrigava os moradores a percorrer longas distâncias para ter acesso ao transporte público. As dificuldades de acesso ao transporte público prejudicavam a qualidade de vida da população, que tinha que se deslocar do bairro para ter acesso ao comércio, ao ensino para os filhos e também para ter assistência à saúde.

Atualmente, o bairro conta com uma população de aproximadamente 60 mil habitantes, o que tende a aumentar devido à construção de diversos edifícios e condomínios que estão substituindo as primeiras casas, bem como ao crescimento da urbanização para áreas antes desocupadas. O bairro expandiu-se e vem perdendo seu caráter predominantemente residencial, principalmente devido a grandes investimentos comerciais que tem atraído em razão do crescimento populacional.

De acordo com os participantes, atualmente, os pontos positivos do bairro estão ligados à melhoria nas áreas da saúde, educação e saneamento básico, com a construção recente de escolas públicas, bom atendimento na Unidade Básica de Saúde e planejamento da rede de esgoto. Outro ponto citado como favorável à situação atual do bairro refere-se a uma ampliação do comércio local, com a construção de um shopping de médio porte e de outros estabelecimentos comerciais.

- Mas hoje a gente conta com um posto policial que funciona, temos hospitais, temos excelentes colégios, o comércio aqui já está muito bom, já temos o shopping!" (M8)

- Temos uma boa infraestrutura. Temos um posto de saúde que funciona, temos uma rede escolar de bom pra ótimo... Tudo o que você precisa tem no bairro, está tudo ao alcance da mão... você tem supermercado, você tem hospital... Aqui você tem farmácia, o que mais tem aqui é farmácia e padaria e salão de beleza. (M3)

- É um bairro que me oferece certo conforto, por exemplo, o transporte, tanto o coletivo quanto o individual, é fácil você chegar nos centros onde você precisa resolver os seus problemas, hoje em dia aqui em (...) tem bancos, quatro agências bancárias, e facilitou muito. (M6)

A sensação de insegurança que os outros causam

Devido ao aumento da violência no local, aferido a partir das queixas dos moradores entrevistados - que provavelmente não se refletem nas estatísticas oficiais em decorrência da subnotificação -, as principais reivindicações dos participantes estão relacionadas, especialmente, à constante sensação de insegurança vivida pelos moradores. Os entrevistados atribuíram esse aumento da violência ao crescimento rápido e desordenado do bairro nos últimos anos. 
- Hoje as pessoas clamam muito pela segurança, pois hoje o que assusta é a insegurança, e eu me preocupo muito quando eu passo e vejo casas com muros mais altos que elas e aquilo vem dizer alguma coisa, diz pra nós e diz para as autoridades. (M3)

- Então, eu acho que essa vinda das pessoas pra (...) foi que causou toda essa situação de violência, né. Porque quando um bairro cresce muito, a tendência também é crescer outro lado não positivo, entendeu? (M7)

Entretanto, em algumas entrevistas, pode-se observar a referência aos bairros vizinhos como os originários da violência local.

- (...) O crescimento de muitas casas novas que iam chegando e muita gente chegando, a violência começou a fluir, a violência é basicamente oriunda desses bairros (vizinhos), devido à facilidade de escape. (M4)

- Um dos aspectos negativos do bairro é a proximidade com a (outro Município) e divisa com outros bairros (...) de onde vêm os marginais. (M9)

- A partir da evolução desse bairro pra esse lado de cá e o crescimento de muitas casas novas que iam chegando e muita gente chegando, a violência começou a fluir, a violência é basicamente oriunda desses bairros (Bairro X, Y, Z), devido à facilidade de escape. (M1)

Os casos de violência considerados mais comuns no cotidiano do bairro se referem a ocorrências recorrentes de furtos, roubos, tráfico de drogas e a um aumento considerável do número de casos de sequestro-relâmpago. Apesar da ênfase no aumento da violência no bairro, alguns participantes julgam esse fenômeno comum à realidade brasileira, que faz parte do dia a dia das pessoas, como quaisquer outros problemas, como exemplificado a seguir:
- Eu adoro, aqui é muito bom pra morar, é um bairro tranquilo, apesar daquilo que já falei, violência tem em todo lugar, tem que andar com cuidado, (violência) tem em (bairro X), tem em (bairro Z). (M8)

- O que está acontecendo aqui é um grande número de sequestros-relâmpagos atualmente no bairro. Muitos assaltos às academias e padarias também. (M4)

- Devido ao grande número de pessoas, há problemas de assalto, sequestro-relâmpago, tráfico de drogas. (M9)

\section{Reações à violência}

Quanto às ações de enfrentamento da violência, verificou-se que ficaram restritas ao âmbito individual. As estratégias mais utilizadas estão ligadas ao uso de portões eletrônicos, alarmes, muros altos nas casas, atenção redobrada no momento de entrada e saída das residências e utilização cada vez mais frequente de seguranças privados, vistos como necessários pela maioria dos participantes.

- (...) Os números de seguranças privados, como nós estávamos falando, triplicaram, e a violência só tende a aumentar, porque ela ocorre basicamente àquele que não está esperando. (M3)

- Eu até comentei, né?... Tem que ter cuidado com esse portão, então agora, na hora de sair, eu verifico, fecho o portão, tenho o cuidado de deixar as portas fechadas... (M5)

Com relação às estratégias coletivas de enfrentamento, os entrevistados declararam ser incipientes ou mesmo inexistentes. Geralmente, têm ligação com a associação de moradores do bairro, considerada pela maioria como uma organização coletiva eficiente, apesar de mencionarem também 
outros espaços coletivos, como as igrejas, o Centro de Convivência para Idosos e os grêmios esportivos, entre outros. Por meio da associação de moradores, as estratégias ou ações coletivas se restringiram à retirada do bairro de um carnaval fora de época que lá ocorria e à contratação de guardas noturnos e seguranças privados.

\section{Avaliação dos órgãos de segurança pública e da participação comunitária}

Ao solicitar dos entrevistados que abordassem a atuação dos órgãos de segurança no combate à violência, as avaliações giraram em torno da atuação da polícia. Os participantes a avaliaram de forma negativa, considerando-a precária e ineficiente. Deixaram claro, no entanto, que é de extrema importância a presença efetiva da polícia para combater a violência no bairro, o que fica explícito nas sugestões dadas quase com unanimidade para o seu enfrentamento: o aumento do efetivo policial nas ruas:

- A segurança no bairro, apesar de ser visível, ela é ineficaz, ineficaz devido à proporção do bairro; nós podemos ser assaltados agora e o rapaz sair andando, e até a polícia chegar, não consegue mais localizá-lo. Essa é uma forma que nós já procuramos priorizar junto à segurança pública, se pudesse se colocar em lugares estratégicos. (M1)

- A segurança hoje é falha, completamente falha em (...) Se os bandidos quiserem e vierem assaltar esse estabelecimento aqui, praticamente saem andando a pé, praticamente não se pega. Então você tem aí uma segurança muito carente mesmo. (M2)

- (...) Porque ela (a polícia) que é o elo. É ela que tem que estar na rua. Este é o papel constitucional dela, é fazer polícia ostensiva, polícia ostensiva é mostrar pela presença... (M3)

Quanto à possibilidade de discussão de questões acerca da violência e da segurança no bairro (como a realização de um seminário), os participantes mostraram-se a favor dessa iniciativa, desde que as pessoas se mobilizassem de forma mais coletiva, abandonando soluções individualistas.

- Acho legal, mas acho que, para fazer algo que mobilize o bairro, acho necessário que seja muito bem divulgado. Acho que as pessoas não irão se mobilizar devido ao comodismo, só se mobilizam quando há algum tipo de interesse particular e não nenhuma ação coletiva. (M9)

- Eu acho que tem que partir realmente da coletividade, onde as pessoas possam estar fazendo, usando uma estratégia, como realmente se prevenir de assaltos. (M7)

Em parte do conteúdo, verificou-se que essas ações coletivas se restringem às iniciativas da associação de moradores:

- Teria que chegar através da associação do bairro, junto a um órgão público para fazer, criar medidas de segurança. (M4)

- Existe uma associação de moradores, com eleições periódicas, mas eu nunca participei bem (...) Acho que ela atua, se não me engano, me parece que o gabarito dos prédios agora, não sei se são oito andares, foi estabelecido através do plano de meta urbano, e com a participação efetiva da comunidade. (M6)

- ... (o bairro) cresceu muito através da associação nessa época, porque tinha várias reivindicações. Por exemplo, aqui nós tínhamos o tal do Pinicão, não sei, vocês são muito jovens. Então, foi um trabalho, uma luta justamente da associação de moradores, na época eu fazia parte, né? (M7)

\section{O pensar juntos: a realização do seminário}

Durante a exposição dos principais resultados relacionados à violência que atinge o bairro, os participantes mostraram interesse participando 
ativamente através do esclarecimento de dúvidas e da formulação de perguntas. Logo após, procurou-se incitar os participantes a refletirem a respeito da criação de estratégias para o enfrentamento do problema e, através do questionamento da falta de mobilização dos próprios moradores, incentivá-los a promover ações coletivas.

Após as discussões e as reflexões produzidas durante o debate, fomentadas sob a coordenação dos pesquisadores, os participantes puderam apresentar algumas propostas relativas ao enfrentamento da violência, considerando-se as particularidades do bairro. Verificou-se que os moradores presentes apresentaram-se receptivos às novas ideias que iam surgindo no debate, davam opiniões e faziam críticas.

\section{As ações propostas}

Quanto às ações referentes aos órgãos públicos, os participantes indicaram serem urgentes as seguintes medidas: maior agilidade no atendimento prestado à população pela polícia, pela Prefeitura Municipal e pelo Estado, planejamento efetivo de manutenção de ruas e avenidas do bairro com locais mais iluminados para inibir assaltos e combate intensivo ao tráfico de drogas, pois alguns traficantes já declararam o chamado toque de recolher no bairro.

Como ações emergenciais do próprio coletivo de moradores, os participantes enfatizaram a necessidade de maior articulação com as organizações sociais já existentes no bairro, a fim de socializar conhecimentos, otimizar recursos, fortalecer a união e estimular a participação na associação de moradores, a criação de mecanismos sociais de forma a aumentar a mobilização coletiva dos moradores, com vistas à realização de melhorias no bairro (por exemplo: realização de campanhas educativas nas escolas e confecção de jornais locais), e maior articulação entre a polícia militar e a Guarda Civil Municipal, na tentativa de somar esforços e delimitar suas competências.

Com relação às ações necessárias à assistência às vítimas de violência, propôs-se que a vítima deve receber atendimento psicológico, para que possa ficar livre de um possível trauma, que deveria haver no Município programas efetivos de assistência e que o Poder Público deve responder às demandas das vítimas por meio de um sistema de segurança mais eficaz, combatendo também a impunidade. Os participantes preocuparam-se também com o melhor acompanhamento e incentivo aos policiais, de modo que eles possam oferecer um atendimento adequado às necessidades da comunidade.

Finalmente, discutiram-se as ações referentes à atuação da polícia e da Guarda Municipal no bairro. Os participantes enfatizaram a necessidade de algumas ações de caráter emergencial, tais como: aumentar o efetivo de policiais que circula pelo bairro, atendendo à proporcionalidade em relação ao número de moradores, oferecer melhores condições de trabalho à polícia (mais viaturas, por exemplo), necessidade de uma ronda policial noturna diariamente, utilização de câmeras nas ruas do bairro, como apoio à atuação da polícia, e também estabelecer melhor interação dos policiais com os moradores do bairro.

\section{Discussão e conclusão}

Os dados obtidos permitem o aprofundamento do debate acerca de algumas questões pertinentes ao cotidiano do bairro, em especial às estratégias de enfrentamento da violência e aos aspectos que se relacionam a esse fenômeno. Um aspecto importante refere-se à interpretação dos moradores sobre a origem da violência. Segundo eles, a violência é sempre inerente aos de fora (Sá, 
2000; Hopenhayn, 2002; Lozano, 2006; Zaluar, 1994; Velho, 1991; Souza, 1995), aos que residem em bairros vizinhos mais carentes e, portanto, considerados de risco.

Pode-se observar que o aumento da violência foi relacionado, pelos entrevistados, ao crescimento do bairro. De acordo com a literatura, tal fato é frequentemente enfatizado, ou seja, há um sentimento de insegurança associado principalmente à urbanização e à expansão das cidades (Sá, 2000).

O que se pode observar é que a responsabilidade da urbanização está em dissonância com o protagonismo de cada sujeito que compõe e constrói a cidade e, portanto, a sociedade em que vive. Essa dificuldade dos participantes em exercer o protagonismo social pode ser identificada na proposição de estratégias que personalizam as ações coletivas em representantes políticos ou em órgãos públicos. Nesse caso, observa-se claramente a ênfase dada pelos participantes à atuação da associação de moradores como única forma possível de viabilizar ações coletivas. Os próprios moradores entrevistados, porém, afirmaram não participar da organização dessa associação, contribuindo para que o movimento se enfraqueça com o passar do tempo, uma vez que é a própria participação que gera o sentimento de cidadania, politiza a procura de soluções para problemas coletivos e renova lideranças comunitárias, como assinalou Machado da Silva (2003).

O que se pôde identificar é que, no bairro pesquisado, a violência tem provocado um processo de individualização dos moradores, reduzindo a participação em espaços coletivos, participação que só ocorre quando a reivindicação coincide com seus interesses pessoais. Essa situação também pode ser constatada no uso cada vez mais frequente de grades e muros altos nas casas, o que fortalece a ideia de condomínio fechado, isolado do espaço externo, que esvazia ainda mais as relações entre os próprios moradores e compromete os processos coletivos do bairro. De acordo com Schilling, "quando não mais sabemos formular projetos comuns que nos orientem para nossa vida comum, construímos mais prisões" (2004, p. 24).

O que se verificou no bairro pode ser interpretado como um enfraquecimento dos órgãos coletivos de atuação pública, gerando assim maior afastamento dos cidadãos. Segundo Hopenhayn (2002), esse é um reflexo direto da globalização na vida urbana que, por meio da individualização e da flexibilização do conceito de trabalho, gera o enfraquecimento das organizações sociais. Esse enfraquecimento é relacionado também à perda de confiança no Estado, como mencionado pelos participantes.

Sá refere-se a esse fato destacando seu duplo sentido:
o dos cidadãos face ao crime e à incapacidade do Estado para resolvê-lo, o do Estado face aos cidadãos pelo fato de eles porem em causa o seu monopólio da violência legítima, porem em causa a existência da Ordem Social que o mesmo Estado representa (2000, p. 03)

Alguns dos aspectos mencionados anteriormente puderam ser observados de forma ainda mais clara durante a realização do seminário. Pode-se mencionar o fato de apenas 14 pessoas (excluindo-se os 6 pesquisadores) terem comparecido ao evento, apesar de toda a divulgação realizada por meio de cartazes espalhados pelas ruas principais do bairro, telefonemas aos participantes entrevistados e convites individuais emitidos pelos Correios, além de nota em um jornal de televisão local.

A escassa sensibilização dos moradores para a participação no seminário confirma o 
que já havia sido verificado nas entrevistas individuais: a violência tem contribuído largamente para aumentar o processo de individualização e isolamento dos moradores do bairro, já que o medo e a sensação constante de insegurança vêm favorecendo, e muitas vezes forçando, o abandono dos espaços públicos $\mathrm{A}$ esse respeito, Molero (2001) adverte sobre o surgimento da ideia de espaço defensivo: “... no centro da cidade há todo um mobiliário urbano planejado para afugentar os vagabundos e para evitar a concentração de grupos de pessoas", o que redunda no cerceamento da liberdade de seus habitantes. Dessa forma, as ações de enfrentamento coletivo da violência tornamse insuficientes e vazias de sentido devido a esse afastamento de cada sujeito da própria coletividade.

Reflexo disso pode ser notado nas soluções apresentadas para o enfrentamento e a redução da violência, que ficaram limitadas às ações de cunho punitivo com indicação, em primeiro lugar, da necessidade de uma polícia ostensiva. Medidas preventivas, cujo foco estaria na redução das diferenças sociais e na promoção dos direitos humanos, não foram citadas pelos participantes, que se afastaram da tendência atual dos debates em torno das estratégias de enfrentamento da violência, como apontaram Moser e Mcilwaine (2006).

Apesar disso, ainda se pôde observar uma disposição dos moradores na mobilização coletiva para o enfrentamento de questões como a violência, quando declararam, durante o seminário, ser imprescindível a criação de estratégias para a participação de todos em prol de uma causa comum, participação que não deve se restringir aos membros da associação de moradores.

É importante notar também que, em diversos momentos, os participantes tenderam a responsabilizar os órgãos públicos, especialmente a polícia, pelo aumento da violência no bairro. Se, por um lado, observou-se nas entrevistas individuais um descrédito na atuação desses órgãos, por outro lado, verificou-se claramente nas estratégias sugeridas pelos participantes, principalmente no decorrer do seminário, uma forte expectativa de que esses mesmos órgãos venham solucionar o problema através do aumento do efetivo e da melhoria das condições de trabalho, entre outros. Desse modo, a falta de confiança declarada parece decorrer prioritariamente de falhas na atuação, e não de um descrédito generalizado em relação à capacidade dos órgãos de segurança pública do Estado.

Ainda assim, é preciso salientar que a falta de confiança no sistema de segurança pública e, em consequência, o descrédito em relação às ações estatais contribuem fortemente para a criação/o aumento da sensação de insegurança e medo, além da fragmentação, do enfraquecimento e mesmo da extinção dos processos coletivos já existentes no bairro. Ao mesmo tempo, depositase a responsabilidade pelo problema da violência apenas em um setor social, qual seja, o Estado. Como informa Schilling:

Há a transferência dos medos, muitas vezes difusos, para a 'segurança', para a lei e a ordem, para o Código Penal, com uma consequente 'sobrecarga de segurança'. É interessante ressaltar que essa 'sobrecarga' é concomitante com a sensação de que estamos mais desamparados do que nunca. Essa 'sobrecarga' aparentemente tem um efeito contrário ao que pretende sanar: aumenta o nosso medo (2004, p. 24)

Os dados obtidos no presente estudo tornam imperiosa a necessidade de se valorizar e de se investir na participação popular, estimulando aqueles pequenos movimentos cotidianos que, em diversos momentos, por serem considerados pouco importantes para a solução de problemas sociais, acabam por ficar invisíveis. Como já salientou Miraglia (2006), essa seria uma das condições para se criar estratégias coletivas eficazes para o combate à violência.

É de suma importância ressaltar, portanto, que as questões relacionadas à violência devem ser, necessariamente, discutidas no âmbito coletivo, a fim de se viabilizar a proposição de ações de enfrentamento e de gerar uma mobilização coletiva capaz de fortalecer e encorajar a vivência mais ativa na comunidade. 


\section{Referências}

\section{Edinete Maria Rosa}

Doutora em Psicologia Social. Professora no Programa de Pós-Graduação em Psicologia da Universidade Federal do Espírito Santo, Vitória - ES - Brasil.

Email: edineter@gmail.com

\section{Lídio de Souza}

Doutor em Psicologia Social. Professor no Programa de Pós-Graduação em Psicologia da Universidade Federal do Espírito Santo, Vitória - ES - Brasil.

\section{Daniela Moraes de Oliveira}

Graduada em Psicologia pela Universidade Federal do Espírito Santo, Vitória - ES - Brasil.

\section{Bianca Izoton Coelho}

Mestra em Psicologia na Universidade Federal do Espírito Santo, Vitória - ES - Brasil.

Endereço para envio de correspondência:

Avenida Fernando Ferrari, 514, Goiabeiras, Vitória, ES. Cep.: 29075-910.

Recebido 06/05/2010, 1a Reformulação 14/11/2011, Aprovado 10/01/2012.

Adorno, S. (2002). Exclusão socioeconômica e violência urbana. Sociologias, 4(8), 84-135.

Bardin, L. (1995). Análise de conteúdo. Lisboa: Edições 70.

Bastos, M. J. R. P., Pereira, J. dos A., Smarzaro, D. C. , Costa, E. F., Bossanel, R. C. L., Oliosa, D. M. S., et al. (2009). Análise ecológica dos acidentes e da violência letal em Vitória, ES. Rev. Saúde Pública, 43(1), 123-132.

Brandão, C. R. (1985). Repensando a pesquisa participante. São Paulo: Brasiliense.

Freire, G. H. (2000). Construindo um hipertexto com o usuário. Ciência da Informação, 29(3), 101-110.

Gomes, W. B. (1987). As aplicações sociais da pesquisa qualitativa. Psicologia: Reflexão e Crítica, 2(1/2), 3-14.

Hopenhayn, M. (2002). A cidadania vulnerabilizada na América Latina. Revista Brasileira de Estudos de População, 19(2), 5-18.

Hughes, P. J. A. (2004). Segregação socioespacial e violência na cidade de São Paulo: referências para a formulação de políticas públicas. São Paulo Perspectiva, 18(4), 93-102.

Lozano, S. G. (2006). Vivir la inseguridad en la ciudad de México. El Cotidiano, 21(135), 18-29.

Machado da Silva, L. A. (2003). Cidadania, democracia e justiça social. Rio de Janeiro. Trabalho apresentado no Encontro Nacional do Fórum Nacional de Reforma Urbana. Recuperado em 15 de nov., 2006 de http://www.ibase.br/anexos/ibase dvb_capitulo3.pdf

Mena, F. C., \& Vega, J. N. (2006). La inseguridad en la ciudad: Hacia uma comprensión de la producción social del miedo. Eure, XXXII(97), 7-16.

Miraglia, P. (2006). Os municípios e a segurança pública. In L. Paula \& S. R. Lima (Org). Segurança pública e violência. São Paulo: Contexto.

Molero, M. N. (2001). Seguridad urbana y miedo al crimen. Polis, Revista de la Universidad Bolivariana, 1(002) Recuperado em 15 julho, 2008 de http://redalyc.uaemex.mx/redalyc/src/inicio/ ArtPdfRed.jsp?iCve $=30500214$

Moser, C. O. N., Winton, A., \& Moser, A. (2001). Violence, fear, and insegurity among the urban poor in Latin America. In M. Fay (Ed.), The urban poor in Latin America (pp. 125-178). Washington, DC: The World Bank.

Moser, C. O. N., \& Mcilwaine, C. (2006). Latin American urban violence as a development concern: Towards a framework for violence reduction. World Development, 34(1), 89-112.

Njaine, K., Souza, E. R., Souza Minayo, M.C., \& Assis, S. G. (1997). A produção da (des)informação sobre violência: análise de uma prática discriminatória. Cadernos de Saúde Pública, 13(3), 405-414.

Peixoto, B. T., Lima, R. S., \& Ottoni, M. D. (2004). Metodologias e criminalidade violenta no Brasil. São Paulo Perspectiva, 18(1), 13-21.

Sá, T. V. (2000). Segurança e seu sentimento na cidade. Coimbra. Trabalho apresentado no IV Congresso Português de Sociologia. Recuperado em 15 de nov., 2006 de http://www. aps.pt/ivcong-actas/Acta047.PDF.

Santos, B. de S. (2005). Pela mão de Alice: o social e o político na pós-modernidade (10a. ed.). São Paulo: Cortez.

Sawaia, B. B. (1996). Comunidade: a apropriação científica de um conceito tão antigo quanto a humanidade. In R. H. F. Campos (Org.). Psicologia social comunitária: da solidariedade à autonomia (9a. ed, pp. 35-53). Petrópolis, RJ: Vozes.

Schilling, F. (2004). A sociedade da insegurança e a violência na escola. São Paulo: Moderna.

Silva, L. A. M. da. (2004). Sociabilidade violenta: por uma interpretação da criminalidade contemporânea no Brasil urbano. Soc. Estado, 19(1), 53-84.

Silveira, A., Silva, B., \& Beato, C. (2006). Prevenção de crimes urbanos: o programa fica vivo. In L. Paula \& R. S. Lima (Orgs.) Segurança pública e violência (pp. 77-88). São Paulo: Contexto.

Soares, L. E. (2005). A esperança como dever. In C. Athayde, M. V. Bill \& L. E. Soares. Cabeça de porco. Rio de Janeiro: Objetiva.

Souza, E. R. (2005). Masculinidade e violência no Brasil: contribuições para a reflexão no campo da saúde. Ciência \& Saúde Coletiva, 10(1), 59-70.

Souza, E. R., \& Lima, M. L. C. (2007). Panorama da violência urbana no Brasil e suas capitais. Ciência \& Saúde Coletiva, 11(Supl.), 1211-1222.

Souza, L. (1995). "Olho por olho, dente por dente": representação de justiça e identidade social. Tese de doutorado, Instituto de Psicologia, Universidade de São Paulo, SP.

Thiollent, M. (1985). Metodologia da pesquisa-ação. São Paulo: Cortez.

Velho, G. (1991). O grupo e seus limites. Revista USP, 9, 23-26

Zaluar, A. (1994). A máquina e a revolta. As organizações populares e o significado da pobreza (2a. ed.). São Paulo: Braziliense.

Waiselfisz, J. J. (2011). Mapa da violência 2011: os jovens do Brasil. Brasília, DF: Instituto Sangari/Ministério da Justiça. 